Botelho MGL, Furtado LG, Lima DA, Pimentel BS, Machado ASO, Almeida Jr JP, Costa MSS \& Pontes NA (2020). Temporal and spatial evaluation of hot spots in Paragominas, PA, Brazil. Research, Society and Development, 9(7): 1-16, e589974501

\title{
Avaliação temporal e espacial de focos de calor em Paragominas, PA, Brasil
}

Temporal and spatial evaluation of hot spots in Paragominas, PA, Brazil

Evaluación temporal y espacial de puntos calientes en Paragominas, PA, Brasil

Recebido: 13/05/2020 | Revisado: 16/05/2020 | Aceito: 19/05/2020 | Publicado: 29/05/2020

\section{Matheus Gabriel Lopes Botelho}

ORCID: https://orcid.org/0000-0002-0514-0382

Universidade do Estado do Pará, Brasil

E-mail: math.botelho2194@gmail.com

Layse Gomes Furtado

ORCID: https://orcid.org/0000-0002-2442-0945

Universidade do Estado do Pará, Brasil

E-mail: layse.furtadog@gmail.com

Darli de Almeida Lima

ORCID: https://orcid.org/0000-0001-5640-0044

Universidade Federal Rural da Amazônia, Brasil

E-mail: eng.darlilima@gmail.com

Brenda dos Santos Pimentel

ORCID: https://orcid.org/0000-0003-1691-9786

Universidade Federal Rural da Amazônia, Brasil

E-mail: brendasantospimentel@gmail.com

Adelia do Socorro Oliveira Machado

ORCID: https://orcid.org/0000-0003-4986-9412

Universidade Federal Rural da Amazônia, Brasil

E-mail: adelia18machado@gmail.com

Jorge Pantoja de Almeida Júnior

ORCID: https://orcid.org/0000-0002-8273-4854

Universidade Federal Rural da Amazônia, Brasil

E-mail: jorgealmeidaufra@gmail.com 
Merilene do Socorro Silva Costa

ORCID: https://orcid.org/0000-0002-9299-6786

Universidade Federal Rural da Amazônia, Brasil

E-mail: merilene@ hotmail.com

Altem Nascimento Pontes

ORCID: https://orcid.org/0000-0002-9001-4603

Universidade do Estado do Pará, Brasil

E-mail: altempontes@gmail.com

\section{Resumo}

Com intuito de compreender os padrões de queimadas no território de Paragominas, Pará, tendo em vista a forte relação com as atividades agropecuárias desenvolvidas na região e as implicações negativas que o uso do fogo proporciona ao meu ambiente, este trabalho tem como objetivo espacializar e analisar o comportamento dos focos de calor no município, nos anos de 2000, 2015 e 2018. Realizou-se o mapeamento das áreas afetadas por queimadas no município para a interpretação visual sobre as imagens normalizadas. Utilizou-se as análises qualitativas e quantitativas para os dados mapeados, com o objetivo de realizar um detalhamento dos dados no que se refere ao panorama de evolução das queimadas. Manuseou-se os dados geoespaciais disponíveis gratuitamente pelo Banco de dados do Programa de Prevenção e Controle de Queimadas e Incêndios Florestais na Amazônia Legal (PROARCO). Empregou-se o método de Kernel para a distribuição espacial dos focos de calor. O total de ocorrência de focos no período compreendido nos anos de 2000, 2015 e 2018 foi de 34.323. Entre os anos de 2015 e 2018, o município apresentou uma diminuição na taxa de ocorrência de focos de calor com 26.728 (77,87\%) e 6.561 (19,11\%), respectivamente. $\mathrm{O}$ ano de 2015 obteve o maior índice de queimadas, mesmo após a intervenção do Estado contra o desmatamento. Portanto, observou-se que as incidências de focos de calor no município de Paragominas, está diretamente ligada às atividades agropecuárias praticadas pelos agricultores que habitam na região, uma vez que a localidade é referência na produção agropecuária na Amazônia.

Palavras-chave: Queimadas; Atividades agropecuárias; Método de kernel; Distribuição espacial. 


\section{Abstract}

In order to understand the burning patterns in the territory of Paragominas, Pará, in view of the strong relationship with the agricultural activities developed in the region and the negative implications that the use of fire provides to my environment, this work aims to spatialize and analyze the behavior of hot spots in the municipality, in the years 2000, 2015 and 2018. The areas affected by fires in the municipality were mapped for visual interpretation on standardized images. Qualitative and quantitative analyzes were used for the mapped data, with the aim of detailing the data regarding the panorama of the evolution of the fires. The geospatial data available for free by the Database of the Program for the Prevention and Control of Burnings and Forest Fires in the Legal Amazon (PROARCO) was handled. The Kernel method was used for the spatial distribution of the hot spots. The total number of outbreaks in the period between 2000, 2015 and 2018 was 34,323. Between the years 2015 and 2018, the municipality showed a decrease in the rate of occurrence of hot spots with $26,728(77.87 \%)$ and $6,561(19.11 \%)$, respectively. The year 2015 had the highest rate of fires, even after State intervention against deforestation. Therefore, it was observed that the incidence of hot spots in the municipality of Paragominas, is directly linked to agricultural activities practiced by farmers who live in the region, since the location is a reference in agricultural production in the Amazon.

Keywords: Burned; Agricultural activities; Kernel method; Spatial distribution.

\section{Resumen}

Con el fin de entender los patrones de quema en el territorio de Paragominas, Pará, en vista de la fuerte relación con las actividades agrícolas desarrolladas en la región y las implicaciones negativas que el uso del fuego proporciona a mi entorno, este trabajo tiene como objetivo espacializar y analizar el comportamiento de los puntos calientes en el municipio, en los años 2000, 2015 y 2018. Las áreas afectadas por incendios en el municipio se mapearon para la interpretación visual en imágenes normalizadas. Se utilizaron análisis cualitativos y cuantitativos para los datos mapeados, con el objetivo de detallar los datos con respecto al panorama de la evolución de los incendios. Se manejaron los datos geoespaciales disponibles gratuitamente por la Base de Datos del Programa de Prevención y Control de Quemaduras e Incendios Forestales en la Amazonía Legal (PROARCO). El método Kernel se utilizó para la distribución espacial de los puntos calientes. El número total de brotes en el período comprendido entre 2000, 2015 y 2018 fue de 34.323. Entre los años 2015 y 2018, el municipio presentó una disminución en la tasa de aparición de puntos calientes con 26,728 
(77.87\%) y 6,561 (19.11\%), respectivamente. El año 2015 tuvo la tasa más alta de incendios, incluso después de la intervención del Estado contra la deforestación. Por lo tanto, se observó que la incidencia de puntos calientes en el municipio de Paragominas, está directamente relacionada con las actividades agrícolas practicadas por los agricultores que viven en la región, ya que la ubicación es una referencia en la producción agrícola en la Amazonía.

Palabras clave: Quemado; Actividades agrícolas; Método del kernel; Distribución espacial.

\section{Introdução}

As queimadas na Amazônia estão fortemente associadas às práticas culturais exercidas por pequenos e grandes produtores rurais em atividades econômicas, como a agricultura e pecuária (Sales et al., 2019). Embora seja uma prática cultural e de baixo custo, elas são consideradas como fator ecológico e de grande importância para o meio ambiente, uma vez que as emissões de gases traços produzidos pela biomassa queimada ocassionam complicações no meio natural e na vida humana. Diante do exposto, é de fundamental importância o fomento de pesquisas dentro dessa temática e de metodologias, como o método de Kernel, capazes de identificar, monitorar e compreender o comportamento das queimadas, principalmente, em regiões que ainda fazem uso dessa prática associada às atividades agropecuárias, a exemplo do município de Paragominas no Estado do Pará.

O número de incêndios no contexto amazônico reflete um cenário preocupante que ocasiona impactos socioeconômicos e ambientais, como a degradação da biodiversidade e da paisagem, juntamente com efeitos negativos na saúde humana e na economia de populações rurais que dependem das florestas para a obtenção de produtos extrativistas que são destinados para a comercialização. Dessa forma, para a preservação ou recuperação das áreas afetadas por queimadas na Amazônia, é necessária a união de esforços comunitários, empresariais, institucionais e governamentais para a criação de medidas integradoras que tenham como objetivo a manutenção da natureza (Bastos et al., 2006).

Na Amazônia, a expansão das fronteiras agrícolas, assim como a modernização da agricultura e da pecuária, estão entre os fatores que mais contribuem para a descaracterização da vegetação original, impactando também a biodiversidade, os solos e as águas (Lorena, 2003). Segundo Valente \& Vettorazzi (2002), o acelerado processo de substituição das paisagens naturais ocorre de fato em função da intensificação do antropismo normalmente visando o uso do solo, o que por sua vez ocasiona a formação de pequenos fragmentos florestais onde anteriormente existiam áreas de florestas equatoriais subperenifólias contínuas. 
O município de Paragominas foi destaque na região amazônica como o maior produtor de bovinos do Estado do Pará de 1983 a 1992, e de madeira em tora de floresta nativa nas décadas de 1980 e 1990 (Sales et al., 2019). Conforme estudos realizados pelo Instituto do Homem e Meio Ambiente da Amazônia (Imazon), em 1990, Paragominas era o maior pólo de produção de madeira do Brasil (Verissímo et al., 1992). Atualmente, concentra a maioria das atividades econômicas desenvolvidas na região amazônica, a saber: criação de gado bovino, exploração de madeira, manejo florestal, reflorestamento, cultivo de soja (e outros grãos) e mineração de bauxita (Sales et al., 2019).

O desmatamento sempre esteve presente na história do município desde a abertura da rodovia Belém-Brasília, na década de 1970 (Vasconcelos \& Novo, 2004). Atualmente, com mais de 100 mil habitantes, Paragominas é tida como modelo de desenvolvimento sustentável para outras cidades da Amazônia (Sales et al., 2019). Em 2011, o município foi inserido no Programa Municípios Verdes (PMV), possibilitando um maior controle de usos e de preservação da cobertura vegetal em localidades rurais por meio do Cadastro Ambiental Rural (CAR) (Sales et al., 2019).

Na última década, o município aumentou a produção de grãos e o reflorestamento, e em 2007, foi o maior produtor paraense de milho, o quarto maior de soja, o quinto de arroz e o terceiro maior produtor de madeira em tora oriunda de florestas plantadas (IBGE, 2017). Quanto a produção mineral no município, é bastante expressiva, pois, o mesmo possui uma reserva de bauxita estimada em dois bilhões de toneladas, uma vez que essa reserva começou a ser explorada em 2007 e, em 2008, respondia por 10\% da produção anual de bauxita do Pará (Pinto et al., 2009).

À vista das modificações que as atividades econômicas desenvolvidas no município de Paragominas interferem no uso e cobertura da terra, alguns estudos de Vasconcelos e Novo (2004), Lorena (2003), Bastos et al. (2006) e Sales et al. (2019) ressaltam a importância da utilização de Sistemas de Informação Geográfica (SIG) e de geotecnologias, como o sensoriamento remoto e o geoprocessamento na identificação, classificação e monitoramento de fenômenos espaciais e de diferentes áreas sujeitas às transformações.

Com intuito de compreender os padrões de queimadas no território de Paragominas, tendo em vista a forte relação com as atividades agropecuárias desenvolvidas na região e as implicações negativas que o uso do fogo proporciona ao meu ambiente, este trabalho tem como objetivo espacializar e analisar o comportamento dos focos de calor no município, nos anos de 2000, 2015 e 2018. 


\section{Metodologia}

A pesquisa se dividiu em duas partes. A primeira se baseou em revisão de literatura no Portal de Periódicos da Capes e no Portal Scielo sobre a incidência de focos de calor em municípios amazônicos, como Paragominas. Tal município, área de estudo desta pesquisa, está localizado na mesoregião do sudeste paraense e tem como municípios limítrofes Ulianópolis, Dom Eliseu, Goianésia do Pará, Ipixuna do Pará e Nova Esperança do Pará (Figura 1). Dispõe de uma população de, aproximadamente, 107 habitantes distribuídos em 19.342,254 km² (IBGE, 2017).

Figura 1: Mapa de localização do município de Paragominas, Pará.

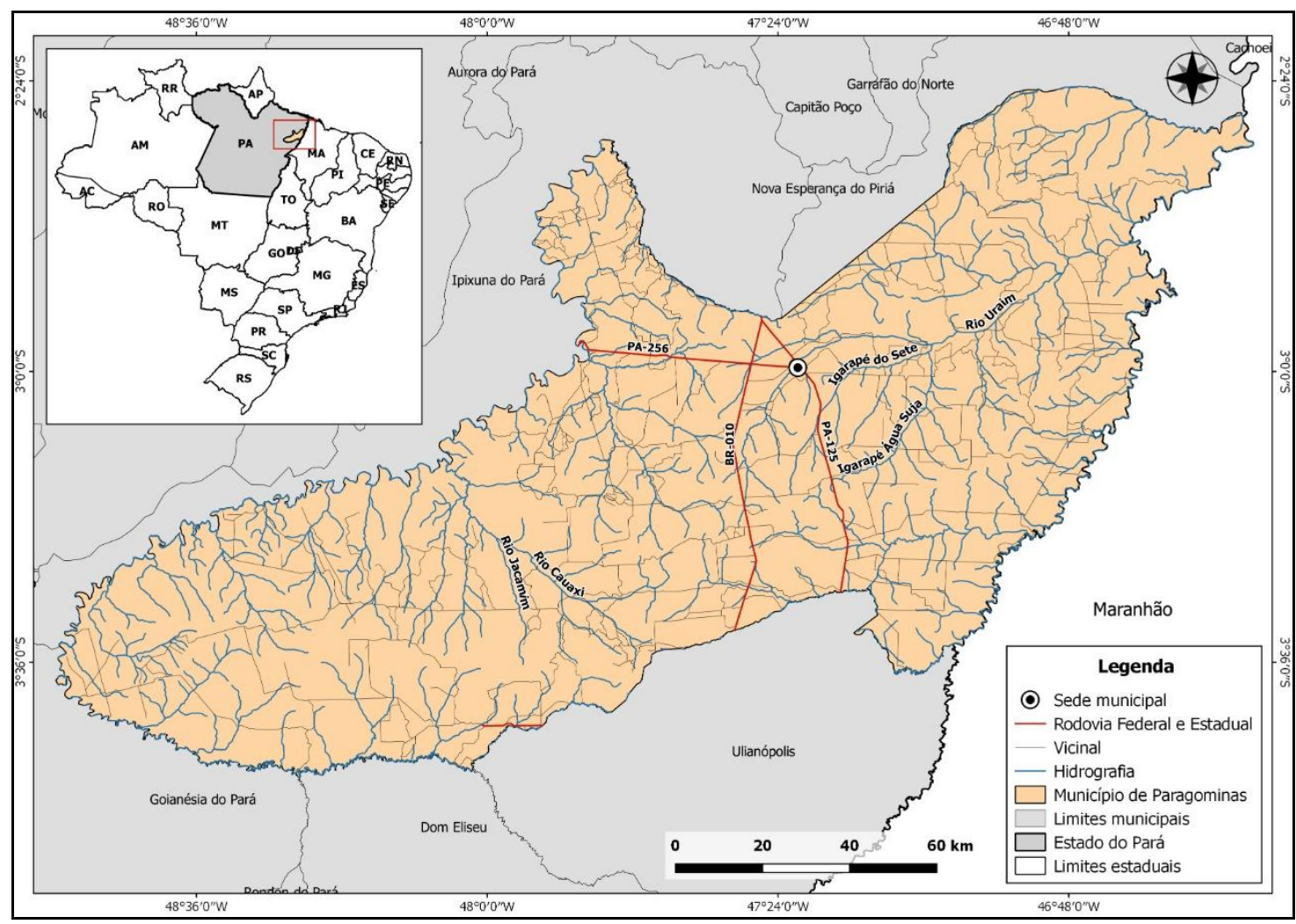

Fonte: Autores (2020).

A segunda parte da pesquisa se fundamentou na utilização de dados geoespaciais disponíveis gratuitamente por instituições governamentais, como as bases territoriais, os dados do Instituto Brasileiro de Geografia e Estatística (IBGE) e os dados de focos de calor extraídos do banco de dados do Programa de Prevenção e Controle de Queimadas e Incêndios Florestais na Amazônia Legal (PROARCO), pelo Instituto Nacional de Pesquisas Espaciais (INPE). 
Realizou-se o mapeamento das áreas afetadas por queimadas no município de Paragominas, Pará, para a interpretação visual sobre as imagens normalizadas, com a finalidade de identificar as características espectrais peculiares registradas na imagem. Utilizaram-se as análises qualitativas e quantitativas para os dados mapeados, com o objetivo de realizar um detalhamento dos dados no que se refere ao panorama de evolução das queimadas por meio de tabela e mapas.

Os dados de focos de calor foram organizados por ano em uma única base de dados, com o propósito de facilitar a visualização, manipulação e edição das informações em sua tabela de atributos. Ambas as bases (territorias e focos de calor) foram manuseadas em formato vetorial (shapefile) em ambiente de Sistema de Informação Geográfica (SIG)ArcGIS 10.1 e QGIS 2.6.1, atribuindo a elas o Sistema de Coordenadas Geográficas e Datum SIRGAS 2000. Com relação as análises estatísticas, utilizou-se a tabela eletrônica do software Excel.

Analisou-se a distribuição dos focos de calor correspondentes aos anos de 2000, 2015 e 2018. Esses dados foram obtidos do processamento diário das imagens termais do sensor AVHRR (Advanced Very-High-Resolution Radiometer), a bordo do satélite NOAA-12, referente ao ano 2000, e o sensor MODIS (Moderate Resolution Imaging Spectrodiometer), acoplado ao satélite meteorológico AQGUA_M-T, referente aos anos de 2015 e 2018, sendo este, o atual satélite de referência do INPE.

Os satélites NOAA-12 e AQGUA_M-T têm órbita polar com distância de 800 km e $710 \mathrm{~km}$, respectivamente, acima da superfície (INPE, 2011). Esses satélites, por meio da validação de campo, conseguem detectar uma frente de fogo, com no mínimo $30 \mathrm{~m}$ de extensão por $1 \mathrm{~m}$ de largura, e são indicados em pixel que variam de $1 \mathrm{~km}^{2}$ ou mais (INPE, 2011). Considerando que uma chama emite energia, principalmente na faixa termal média de 3,7 $\mu \mathrm{m}$ a 4,1 $\mu \mathrm{m}$ do espectro óptico, assim, para identificar os focos de calor, são utilizadas imagens que tenham essa faixa característica, para então selecionar os pixels com maior temperatura (Abreu et al., 2016).

Segundo o INPE (2011), existem fatores que limitam a detecção, como: as frentes de fogo com menos de 30m de extensão; fogo apenas no chão de uma floresta densa, sem atingir a copa de árvores; ocorrência de nuvens, impossibilitando a visualização; queimada de pequena duração e fogo em encosta de montanha. Ressalta-se que a identificação remota dos focos de calor não indica, necessariamente, a existência de queimadas, apesar da maioria está relacionada. Isso porque a relação foco versus queimada não é direta nas imagens de satélite (Araújo et al., 2013). Um foco indica a existência de fogo em um pixel, que varia de $375 \mathrm{~m} \mathrm{x}$ $375 \mathrm{~m}$ até $5 \mathrm{~km}$ x $4 \mathrm{~km}$, dependendo do satélite, assim, nesse pixel, pode haver uma ou várias 
queimadas diferentes onde a indicação será de um único foco, da mesma maneira que uma queimada extensa poderá ser detectada em alguns pixels vizinhos, isto é, vários focos estarão associados a uma única e grande queimada (Araújo et al., 2013).

Após a conversão dos dados tabulares para os dados vetoriais, os mesmos foram sobrepostos à área de estudo para iniciar os procedimentos de interpretação das informações e criação de dados derivados. Em seguida, foram gerados por meio do algoritmo estimador de densidade de Kernel, dados matriciais de densidade de focos de calor acumulados para os anos de 2000, 2015 e 2018.

A partir da distribuição espacial dos focos de calor pela análise de Kernel, foi possível verificar as áreas de maior incidência nos anos mais críticos. Esta análise visava estimar suavizadamente a densidade de focos de calor por unidade de área, que é caracterizada como alternativa para análise geográfica do comportamento de padrões (Oliveira \& Oliveira, 2017). De acordo com Vasconcelos \& Novo (2004), essa contagem de área é ponderada pela distância de cada evento ao ponto de referência dentro de um dado raio, sendo uma propriedade de relevância para a análise de tendência de um processo estocástico espacial.

\section{Resultados e Discussão}

O mapeamento das áreas de queimadas em municípios amazônicos está diretamente ligado aos dados de focos de calor que são diariamente disponibilizados pelo INPE, pois, os mesmos são indicativos potenciais de queimadas (Sales et al., 2019). Os resultados do mapeamento do número de focos de calor detectados no município de Paragominas são apresentados na Tabela 1. O total de ocorrência de focos no período compreendido nos anos de 2000, 2015 e 2018 foi de 34.323. O maior pico de focos detectado foi no segundo ano de observação, 2015 (77,87\% de focos de calor). Segundo Herrmann (2011), a detecção dos focos de calor é imprescindível para municípios e corredores ecológicos propícios à queimadas e desmatamentos, já que favorece a incorporação de um planejamento regional de conservação e facilita um gerenciamento territorial e ambiental adequados. 
(CC BY 4.0) | ISSN 2525-3409 | DOI: http://dx.doi.org/10.33448/rsd-v9i7.4501

Tabela 1: Distribuição de focos de calor no município de Paragominas (PA) nos anos 2000, 2015 e 2018.

\begin{tabular}{|c|c|c|}
\hline Ano & Número de focos de calor & $\%$ \\
\hline 2000 & 1.034 & 3,02 \\
\hline 2015 & 26.728 & 77,87 \\
\hline 2018 & 6.561 & 19,11 \\
\hline Total & 34.323 & 00 \\
\hline
\end{tabular}

Fonte: Autores (2020).

A maior concentração $(77,87 \%)$ das incidências foi em 2015 com 26.728 focos, seguido por 2018 com 6.561 focos. Segundo Herrmann (2011), os dados analisados por pesquisas relacionadas aos focos de calor em municípios e corredores ecológicos podem ser úteis para a calibração e atualização do sistema do INPE. Nesta instituição verifica-se uma limitação de informações sistemáticas de ocorrência de incêndios em algumas regiões do Brasil, como na Amazônia.

Até 2008 a cidade de Paragominas já tinha sofrido uma perda de $43 \%$ de sua área de floresta por conta das atividades locais que provocavam o desmatamento, e este fato resultou na entrada da cidade na lista do Ministério do Meio Ambiente como um dos municípios que mais desmatavam a floresta amazônica, o que culminou na operação Arco de Fogo no município também em 2008 (Sales et al., 2019).

Bastos et al. (2006) realizaram um estudo sobre os aspectos climáticos para as atividades agrícolas em Paragominas entre 1973 a 2004, e constataram que houve anomalias associadas à flutuação de totais de chuva por ano. Havendo oscilação entre déficits e excedentes de água no município. Sendo assim, os autores concluíram que essa anomalia é recorrente no município entre os referidos anos. Não ocorrendo relação com queimadas ou desmatamentos nos anos estudados.

Verifica-se que fatores específicos podem ser destacados como principais causas das incidências de focos de calor em Paragominas, como a construção de ferrovias, incêndios florestais e as queimadas utilizadas na prática agropastoril que realiza o uso do fogo para a renovação de pastagens ou para a agricultura. Evidencia-se que ocorre um quadro de práticas agrícolas tradicionais que precisam sofrer intervenções controladoras e sistemáticas, com a finalidade de combater e prevenir as intensas degradações ambientais sobre a paisagem do município. 
Sales et al. (2019) verificaram que ocorre um aumento da extensão de queimadas nos anos de 2015 e 2016 no município de Paragominas, mediante a observação do crescimento impactante e gradativo da ocorrência da ação do fogo neste período estudado. Os mesmos autores verificaram que esses resultados estão diretamente ligados ao ciclo hídrico da região. Havendo déficits e excedentes de água ligados às oscilações de precipitações no município, causados pela ocorrência de queimadas nos referidos anos. Além de pressupor que houve condições favoráveis para o desenvolvimento do fogo, devido ao clima local caracterizado por temperaturas elevadas. Segundo Costa \& Fleury (2015), o clima no município é definido por uma temperatura média anual elevada, em torno de $25^{\circ} \mathrm{C}$, caracterizado como úmido e mesotérmico, influenciando na distribuição não igualitária das chuvas durante o ano, e ocasionando eventos extremos como cheias de rios, em meses (janeiro a junho) de maior precipitação.

No ano de 2015, houve compatibilidade entre o mapeamento das áreas de queimadas com os focos de calor em Paragominas, porém, em 2016, não houve essa coincidência, havendo uma inconstância temporal no que se refere à ação do fogo proveniente de queimadas no referido município (Sales et al., 2019). O potencial do fogo é significativo em condições climáticas favoráveis, uma vez que na região amazônica os períodos de estiagem contribuem para a intensificação das queimadas, principalmente, nos anos de ocorrência do fenômeno El Niño caracterizado por um aquecimento anormal das águas superficiais do oceano Pacífico (Bastos et al., 2006). Esse fenômeno foi observado por Barbosa (2010), que analisou a distribuição de queimadas no período de 1999 a 2009 no estado de Roraima, constatando a coincidência de ação do fogo com o El Niño, nos anos avaliados.

A cidade de Paragominas foi a primeira, ao lado do município Lucas do Rio Verde/Mato Grosso, a implantar o projeto "Município Verde", realizado pelo Governo Federal entre 2007 e 2008, para municípios da Amazônia, uma vez que foi signatário do programa em 2009. Nesse sentido, o desmatamento teve uma queda nas ocorrências de focos de calor. Porém, houve um novo aumento no ano de 2015, em períodos de estiagem, provocados, principalmente, por queimadas de limpeza, método ainda muito utilizado na região (Sales, et al., 2019). Isso se deve ao fato de que em 2015, o município de Paragominas se consolidou como um dos principais municípios de potencial agropecuário na região amazônica (Sales, et al., 2019).

No ano de 2000, início da série dos focos de calor estudados, observa-se a menor incidência em comparação aos anos sequentes, visto que a localidade ainda não era destaque na produção de pastagens a nível regional (Figura 2). 
(CC BY 4.0) | ISSN 2525-3409 | DOI: http://dx.doi.org/10.33448/rsd-v9i7.4501

Figura 2: Análise de Kernel para o município de Paragominas-PA, no ano de 2000.

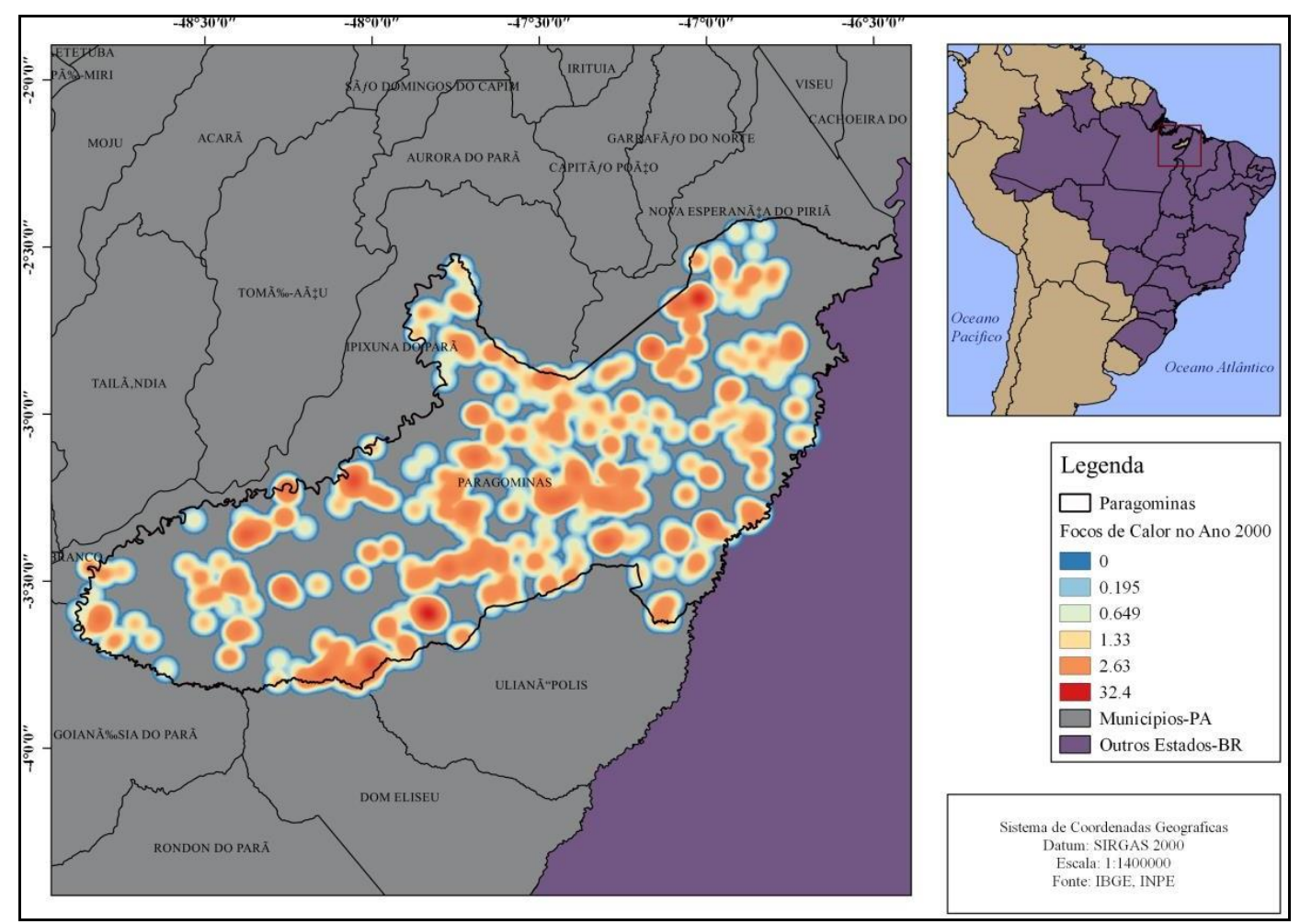

Fonte: Autores (2020).

Entre os anos de 2015 e 2018, o município apresentou uma diminuição na taxa de ocorrência de focos de calor com $26.728(77,87 \%)$ e $6.561(19,11 \%)$, respectivamente. O ano de 2015 obteve o maior índice de queimadas, mesmo após a intervenção do Estado contra o desmatamento (Figura 3). Dessa forma, pode-se aferir que em 2015 houve um maior número de queimadas para finalidades agropecuárias no município de Paragominas, uma vez que esse território se destaca pela produção de pastagens no referido ano. Os agricultores da localidade ainda utilizam técnicas rudimentares com a utilização do fogo para a agricultura e formação de pastos, contribuindo de forma significativa para a geração de focos de calor. 
(CC BY 4.0) | ISSN 2525-3409 | DOI: http://dx.doi.org/10.33448/rsd-v9i7.4501

Figura 3: Análise de Kernel para o município de Paragominas-PA, no ano de 2015.

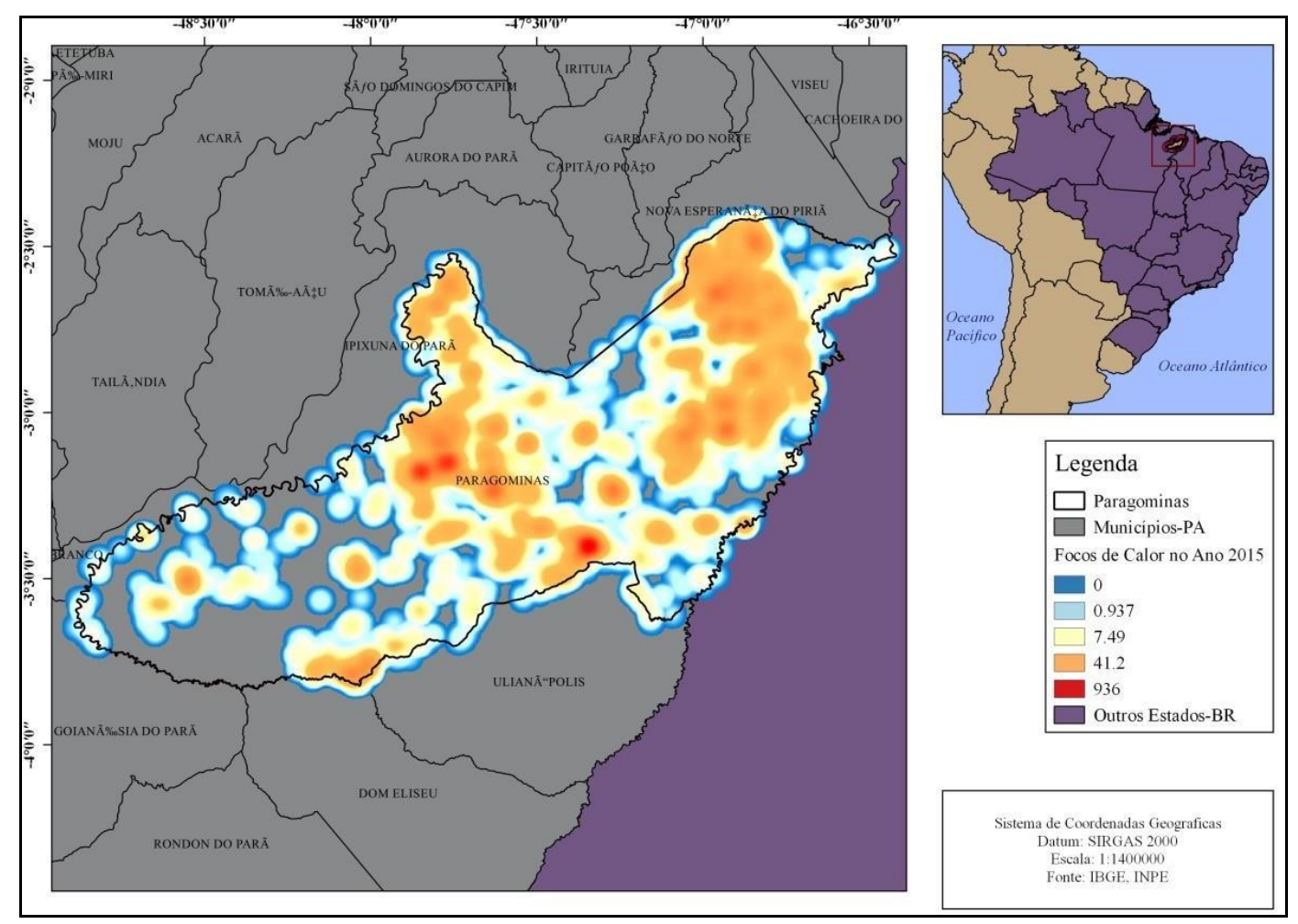

Fonte: Autores (2020).

No ano de 2018, pode-se averiguar que houve uma queda no número de focos de calor no município (Figura 4). Pois, os agricultores da região têm realizado práticas agrícolas menos agressivas ao meio ambiente com práticas sustentáveis, como a integração lavoura-pecuária-floresta, que se caracteriza como uma estratégia de produção com a integração de diferentes sistemas produtivos (florestais, agrícolas e pecuários) que visa a sustentabilidade nos meios de produção, o que ocasiona menos incêndios florestais. Esse fato se deve, principalmente, ao incentivo do Estado em realizar práticas de desenvolvimento sustentável na região amazônica para combater queimadas e desmatamentos. 
Figura 4: Análise de Kernel para o município de Paragominas-PA, no ano de 2018.

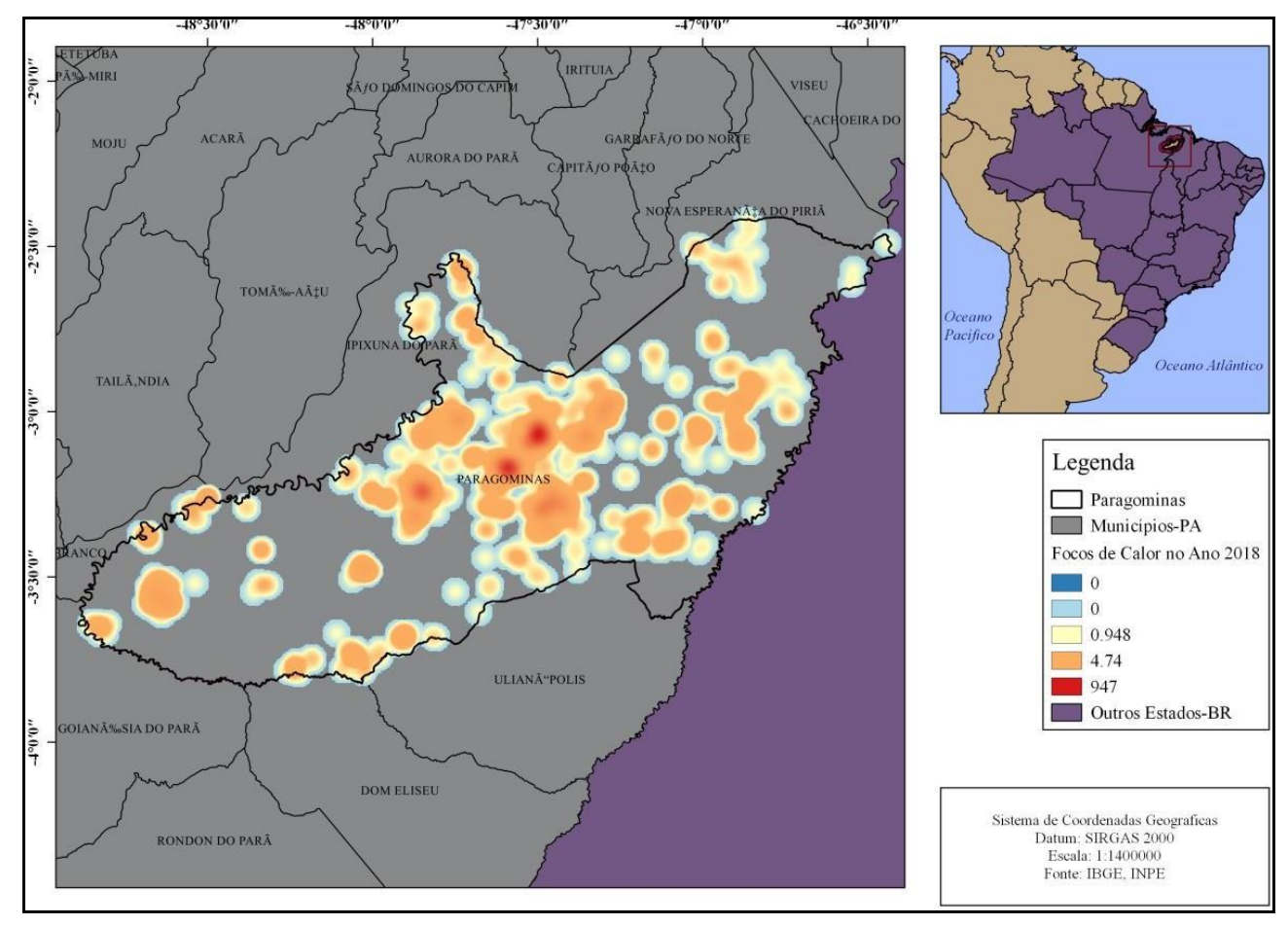

Fonte: Autores (2020).

Analisando os mapas de calor, foi possível verificar a quantidade de focos de calor em relação a cada ano, dentro do período estudado. Por meio desta ferramenta foi viável analisar que ocorre uma relação com as áreas de queimadas e os dados de focos de calor, juntamente, com os Projetos de Assentamento Agrícola (agricultura familiar), em Paragominas, pois, verifica-se que as possíveis ignições do fogo estão relacionadas às atividades agropecuárias.

A paisagem de Paragominas é afetada por efeitos nocivos, uma vez que a dinâmica de ocupação e de uso da terra é recorrente sobre as mudanças climáticas, provenientes de queimadas, alterando de forma significativa a temperatura, umidade, velocidade do ar, radiação solar, vegetação, permeabilidade do solo, ocorrência de chuvas, águas superficias e entre outros aspectos (Sales et al., 2019). O histórico de focos de calor no município de Paragominas pode ser uma manifestação de um contexto padronizado de inadequados manejos de recursos naturais, no que se refere aos parâmetros produtivos e ambientais.

\section{Considerações Finais}

Portanto, observou-se que as incidências de focos de calor no município de Paragominas, está diretamente ligada às atividades agropecuárias praticadas pelos 
agricultores que habitam na região, uma vez que a localidade é referência na produção agropecuária na Amazônia, com a utilização de técnicas rudimentares, ocasionando impactos ambientais significativos, como o desmatamento causado por meio de queimadas, o que fica evidente no ano de 2015, como o período que possui o maior número de focos de incêndios.

A diminuição dos focos de calor no intervalo de 2015 para 2018 se deve à intervenção de políticas públicas na região para combater problemas ambientais como a intensa degradação de recursos naturais, desmatamentos e queimadas. O método utilizado na pesquisa é de extrema importância para subsidiar a gestão local, de modo a otimizar na identificação e monitoramento das áreas atingidas pelo fogo, possibilitando uma ação eficiente de prevenção e combate às queimadas para potencializar o manejo florestal sustentável.

A concepção ambiental local precisa se desenvolver para haver uma consciência produtiva integrada, com o objetivo de alcançar resultados eficientes sem a intensa degradação da natureza. Dessa forma, por meio dessa pesquisa, existem possibilidades de maiores estudos no que se refere à gestão sustentável de municípios amazônicos, como a análise de zonas de adequação produtiva e ambiental para o prosseguimento do desenvolvimento sustentável, assim como, a avaliação do planejamento do uso de terras que visam o fortalecimento do manejo florestal.

\section{Referências}

Abreu, F. D. A., \& Souza, J. D. S. A. (2016). Dinâmica espaço-temporal de focos de calor em duas terras indígenas do Estado de Mato Grosso: uma abordagem geoespacial sobre a dinâmica do uso do fogo por Xavantes e Bororos. Floresta e Ambiente, 23(1), 1-10.

Araujo, H. J. B. D., Oliveira, L. C. D., Vasconcelos, S. S. D., \& Correia, M. F. (2013). Danos provocados pelo fogo sobre a vegetação natural em uma floresta primária no estado do Acre, Amazônia brasileira. Ciência Florestal, 23(2), 297-308.

Bastos, T. X., Silva, G., Pacheco, N. A., \& Figueiredo, R. D. O. (2006). Informações agroclimáticas do município de Paragominas para o planejamento agrícola. In Embrapa Amazônia Oriental-Artigo em anais de congresso (ALICE). In: Congresso Brasileiro de Meteorologia, 14., 2006, Florianópolis. Anais... Florianópolis: SBMET. 
Barbosa, R. I. Distribuição espacial e temporal dos focos de calor no estado de Roraima para o período de janeiro - 1999 a dezembro - 2009 (satélites NOAA 12 - N E NOAA 15 N). (2010). Relatório técnico-científico. Comitê de Prevenção e Combate a Incêndios Florestais de Roraima/Instituto Nacional de Pesquisas Amazônicas, Boa Vista.

Costa, J. M., \& Fleury, M. F. (2015). O programa "Municípios Verdes": estratégias de revalorização do espaço em municípios paraenses. Ambiente \& Sociedade, 18(2), 61-76.

Herrmann, G. (2011). Incorporando a teoria ao Planejamento Regional da conservação: a experiência do corredor ecológico da mantiqueira. Belo Horizonte: Valor Natural. 228p.

IBGE. (2017). Instituto Brasileiro de Geografia e Estatística. Diretoria de Pesquisas, Coordenação de População e Indicadores Sociais. Acesso em 15 de janeiro de 2020, em: http://cod.ibge.gov.br/233W4.

INPE. (2011). Instituto Nacional de Pesquisas Espaciais. Perguntas frequentes [online]. São José dos Campos: INPE. Acesso em 30 de abril de 2020, em: http://queimadas.dgi.inpe.br/queimadas/portal/informacoes/perguntas-frequentes\#p9.

Lorena, R. B. (2003). Evolução do uso da terra em porção da Amazônia ocidental (Acre), com uso de técnicas de detecção de mudanças. Doctoral dissertation, Dissertação de mestrado. INPE. São José dos Campos.

Oliveira, U. C., \& de Oliveira, P. S. (2017). Mapas de Kernel como subsídio à gestão ambiental: análise dos focos de calor na bacia hidrográfica do rio Acaraú, Ceará, nos Anos 2010 a 2015. Espaço Aberto, 7(1), 87-99.

Pinto, A., Amaral, P., Souza Jr, C., Veríssimo, A., Salomão, R., Gomes, G., \& Balieiro, C. (2009). Diagnóstico socioeconômico e florestal do município de Paragominas. Belém: Imazon. Acesso em 29 de abril de 2020, em: https://imazon.org.br/PDFimazon/Portugues/outros/iagnostico-socioeconomico-e-florestaldo.pdf. 
Sales, G. M., Pereira, J. L. G., Thalês, M. C., Poccard-Chapuis, R., \& de Almeida, A. S. (2019). Emprego dos focos de calor na avaliação das queimadas e em incêndios florestais em Paragominas, Pará, Brasil. Boletim do Museu Paraense Emílio Goeldi-Ciências Naturais, 14(1), 55-77.

Valente, R. O. A., \& Vettorazzi, C. A. (2002). Análise da estrutura da paisagem na Bacia do Rio Corumbataí, SP. Scientia Forestalis, (62), 114-129.

Vasconcelos, C. H., \& Novo, E. M. L. D. M. (2004). Mapeamento do uso e cobertura da terra a partir da segmentação e classificação de imagens-fração solo, sombra e vegetação derivadas do modelo linear de mistura aplicado a dados do sensor TM/Landsat5, na região do reservatório de Tucuruí-PA. Acta Amazônica, 34(3), 487-493.

Veríssimo, A., Barreto, P., Mattos, M., Tarifa, R., \& Uhl, C. (1992). Logging impacts and prospects for sustainable forest management in an old Amazonian frontier: the case of Paragominas. Forest ecology and management, 55(1-4), 169-199.

\section{Porcentagem de contribuição de cada autor no manuscrito}

Matheus Gabriel Lopes Botelho - 20\%

Layse Gomes Furtado - 15\%

Darli de Almeida Lima - 15\%

Brenda dos Santos Pimentel $-10 \%$

Adelia do Socorro Oliveira Machado - 10\%

Jorge Pantoja de Almeida Júnior - 10\%

Merilene do Socorro Silva Costa $-10 \%$

Altem Nascimento Pontes - 10\% 